\title{
Articulations of Family Life and Organization for Happy Life
}

\author{
Ali Fatah Bin Jamal: Mohammad Zakari \\ Master of Social Sciences, Universiti Sains Malaysia, Penang, Malaysia \\ https://doi.org/10.47814/ijssrr.v3i4.55
}

\begin{abstract}
Family is an instrumental for the development of the nation and culture. Different culture have different perception regarding the importance of the family. There are also difference in types of family, and social scientists measure the characteristics of the family in different cultures. In this paper we tried to explore the importance of family for happy life. In order to test the hypothesis, the chosen research question, data from the German General Social Survey 2014 is used. Based on statistical analysis and their results, both hypothesis are supported. These hypotheses and their results indicates that the people who spend their leisure time with family, they consider and think that family is important. On the other hand, people who are more interested in soaps and sitcoms, they may think that, all problems and issues are part of life but family is still important for them.
\end{abstract}

Keyword: Family Importance; Soaps and Sitcoms; Leisure Time and Family Importance

\section{Introduction}

Entertainment is a form of activity that holds the attention and interest of an audience or gives pleasure and delight. It can be an idea or a task, but is more likely to be one of the activities or events that have developed over thousands of years specifically for the purpose of keeping an audience's attention. Although people's attention is held by different things, because individuals have different preferences in entertainment, most forms are recognizable and familiar. Storytelling, music, drama, dance, and different kinds of performance exist in all cultures, were supported in royal courts, developed into sophisticated forms and over time became available to all citizens. The process has been accelerated in modern times by an entertainment industry that records and sells entertainment products. Entertainment evolves and can be adapted to suit any scale, ranging from an individual who chooses a private entertainment from a now enormous array of pre-recorded products; to a banquet adapted for two; to any size or type of party, with appropriate music and dance; to performances intended for thousands; and even for a global audience.

The experience of being entertained has come to be strongly associated with amusement, so that one common understanding of the idea is fun and laughter, although many entertainments have a serious purpose. This may be the case in the various forms of ceremony, celebration, religious festival, or satire for example. Hence, there is the possibility that what appears as entertainment may also be a means of achieving insight or intellectual growth. 
An important aspect of entertainment is the audience, which turns a private recreation or leisure activity into entertainment. The audience may have a passive role, as in the case of persons watching a play, opera, television show, or film; or the audience role may be active, as in the case of games, where the participant/audience roles may be routinely reversed. Entertainment can be public or private, involving formal, scripted performance, as in the case of theatre or concerts; or unscripted and spontaneous, as in the case of children's games. Most forms of entertainment have persisted over many centuries, evolving due to changes in culture, technology, and fashion for example with stage magic. Films and video games, for example, although they use newer media, continue to tell stories, present drama, and play music. Festivals devoted to music, film, or dance allow audiences to be entertained over a number of consecutive days.

Some entertainment, such as public executions, are now illegal in most countries. Activities such as fencing or archery, once used in hunting or war, have become spectator sports. In the same way, other activities, such as cooking, have developed into performances among professionals, staged as global competitions and then broadcast for entertainment. What is entertainment for one group or individual may be regarded as work or an act of cruelty by another.

The familiar forms of entertainment have the capacity to cross over different media and have demonstrated a seemingly unlimited potential for creative remix. This has ensured the continuity and longevity of many themes, images, and structures.

According to the Population Reference Bureau (2000) (as cited in Enrique, J., Howk, H., \& Huitt, W. (2007) "family can be a group of people held together by birth, marriage or adaptation or by common residence or close emotional attachments" The research question we have chosen is related to German society. We have opted this question because in modern western society's individualization is growing and therefore the value of the family might lose its importance. Therefore, the research question of this paper is:

\section{How Can Importance of Constituting a Family Be Explained?}

Family is an instrumental for the development of the nation and culture. Different culture have different perception regarding the importance of the family. There are also difference in types of family, and social scientists measure the characteristics of the family in different cultures. In Unites States of America, the 1960's civil rights and feminist movements resulted in a transformation in attitude towards family behaviors (Evans, 2004). The theory behind the constituting a family is important may depends on your use of media and leisure time which you spend with your family.

\section{H1. The more you spend your leisure time with family the more you consider that constituting family is important.}

Family plays a crucial role in defining the person's actions, influencing personal life and decisions, in society. On the other hand, people who are not much habitual to live alone or spend their leisure time with family, they consider that constituting a family is important for their happy life. People have their own ways to entertain themselves and spend their leisure time, but in the internet age, sometime people feel lonely and irritated to use internet, and they want to spend some time without electronic gadgets and prefer to spend time with their family members.

\section{H2. The more people watch soaps and sitcoms the more they are in favor of constituting a family is important.}

TV shows and series might have impact on opinion about constituting a family. People who regularly watch soaps and sitcoms and see many problems are going on in family, but they may still consider that, this is the part of family matters and consider family is important for happy life. In order to test the 
hypothesis, the chosen research question, data from the German General Social Survey 2014 is used. For our research we use the following variables.

1. Dependent variable: "Constituting a family is Important"

2. Independent variables: "Interest in soaps and sitcoms and spend leisure time with family"

\section{Operationalization}

In order to get necessary data for analysis, the relevant questions were selected from the questionnaire. The first was refereeing to the dependent variable (constituting a family is importance) is:

\section{Do you think one needs a family to be really happy, or do you think one can be just as happy} living on one's own?

The respondents asked to choose between "Needs a family" "Just as happy on one's own" "Happier on one's own" and "Undecided" for the question. First we check the correlation and reliability test to build an index and results allow to build an index of independent variable because dependent variable is only one and no more variables and questions related to dependent variable. We reverse the scale and put into three groups and the reason is, the fourth option is "undecided" we do not know, either they consider family is important or they are happy alone so, we decided to put second and fourth into one group. New values assigned to them from 1- "Low Importance" 2- "Medium Importance" and 3- "High Importance", and new variable called "Family Importance". For the first hypothesis, one relevant question was in the survey:

"And what about these activities? Please tell me here too, how often you do the following in your leisure time.

\section{Visit or be visited by family members or relatives}

\section{Play cards or games with the family"}

In both cases options are "Every day" "At least once a week" "At least once a month" "Less often" and "Never". We checked the reliability of the scale it's rather low but still can be used for index and "family value" is new variable, and first independent variable. The value of this variable is 1 "Never" to 5 "Very Often" and for crosstabs it's recoded into three groups 1 "Low" 2 "Medium" and 3 "High" to be equal as possible in terms of percentages, as it can be, for better comparison. For the t-test, we will use two extreme values 1 and 2 .

For the media related (second hypothesis) question is "please tell me how interested you are in each kind of program on the list: very strongly, strongly, middling, little or not at all? Soaps and Sitcoms is the most relevant option and we flipped the scale ("1-very low interest" to " 5 -very high interest") and the second independent variable is called "Soaps and Sitcoms". It has interval scale and values are from 1 (low interest) to 5 (high interest). For the crosstab variable is recoded into three groups 1 is "low Interest" 2 is "Medium Interest" and 3 is "High Interest" for better comparison, and for the t- test we will use two groups 1 and 2.

\section{Findings}

For checking the relationship between importance of family and interest in soaps and sitcoms and time spend with families, several statistical tests were applied using SPSS: correlation, crosstabs, t-test and regression analysis. 


\section{a. Correlations}

The correlation analysis result (Table 1) shows a positive correlation ( $\mathrm{r}=.119)$ between family importance and spend leisure time with the family and there is small but positive correlation $(\mathrm{r}=.104)$ between family importance and interest in soaps and sitcoms. Both results are highly significant $(\mathrm{p}<.000)$ therefore first hypotheses and second hypotheses supported that mean the people who watch more soaps and sitcoms more in favor of constituting a family is important for happy life. The people who spend more leisure time with family, more they consider that constituting a family is important.

\begin{tabular}{|l|l|l|}
\hline & Family Value & Soaps and Sitcoms \\
\hline Family Importance & $\mathrm{r}=.119$ & $\mathrm{r}=.104$ \\
\hline $\mathbf{N}=$ & 3471 & 3372 \\
\hline $\mathbf{P}$ & $=<.000$ & $=<.000$ \\
\hline
\end{tabular}

Table: 1 Correlation between family importance and family value / soaps and sitcoms.

\section{b. Crosstabs}

The results in the first column of Table: 2 (Family Value Cross) shows a clear relationship between two variables. Only (1.8\%) people consider the less time spend with family the low interested in constituting a family is important, and even lower (1.0\%) people consider the good they spend time with family, show less family is important for them. On the other hand (59.6\%) people consider the less you spend leisure time with family the lower family importance, compared to (76.5\%) people consider the more time spend and visit family the more you believe that constituting a family is important. The results are significant (p. $<001$ and $\mathrm{Chi}^{2}=37.7$ ), first hypothesis is supported. The second column, shows, the high interest in constituting a family the higher the interests in soaps and sitcoms, (78.6\%) people give highly importance to family compared to those who show low interest in soaps and sitcoms (67.0\%). On the other side, the more people have low interest in watching soaps and sitcoms have indicates low interest $(1.7 \%)$ in making a family is important for happy life, compared to those who manifest higher interest $(1.3 \%)$. These numbers are very low because of the family importance for happy life, dependent variable has already have $70 \%$ answer that family is important for happy life. These low numbers are hard to interpret because low percentage seems to be very low and hard to extract the meaning. The results are significant (p. $<001$ and $\mathrm{Ch}^{2}=35.7$ ), and second hypothesis also confirmed.

\begin{tabular}{|c|c|c|c|c|c|c|c|}
\hline & & \multicolumn{3}{|c|}{ Family Value Cross } & \multicolumn{3}{|c|}{ Soaps and Sitcoms Cross } \\
\hline & & Low & Medium & High & $\begin{array}{l}\text { Low } \\
\text { Interest }\end{array}$ & $\begin{array}{l}\text { Medium } \\
\text { Interest }\end{array}$ & $\begin{array}{l}\text { High } \\
\text { Interest }\end{array}$ \\
\hline \multicolumn{2}{|c|}{$\mathbf{N}=$} & 399 & 2242 & 826 & 1616 & 991 & 761 \\
\hline \multirow[t]{3}{*}{$\begin{array}{c}\text { Family } \\
\text { Importance }\end{array}$} & $\begin{array}{l}\text { Low } \\
\text { Importance }\end{array}$ & $1.8 \%$ & $1.6 \%$ & $1.0 \%$ & $1.7 \%$ & $1.2 \%$ & $1.3 \%$ \\
\hline & $\begin{array}{l}\text { Medium } \\
\text { Importance }\end{array}$ & $38.6 \%$ & $27.9 \%$ & 22.95 & $31.4 \%$ & $26.3 \%$ & $20.1 \%$ \\
\hline & $\begin{array}{l}\text { High } \\
\text { Importance }\end{array}$ & $59.6 \%$ & $70.5 \%$ & $76.5 \%$ & $67.0 \%$ & $72.5 \%$ & $78.6 \%$ \\
\hline & & \multicolumn{3}{|c|}{ Chi square $=37.7 \mathrm{p}=<.001$} & \multicolumn{3}{|c|}{ Chi square $=35.7 p<.001$} \\
\hline
\end{tabular}

Table2: Crosstabs between Family Importance and Family Value cross/ Interest in soaps and sitcoms 


\section{c. T-Test}

The T-test confirms the result of the previous tests. Table 3: shows the difference between means of family importance levels are visible for both independent variables. The difference is not much bigger in case of family value $T(0.12)$ than the case of interest in soaps and sitcoms $(0.10)$ which links to the correlation and crosstabs results. Highly significance results are for both cases $(\mathrm{p}<.001)$, both hypotheses are supported.

\begin{tabular}{|l|l|l|l|l|}
\hline & \multicolumn{2}{|l|}{ Family Value T } & \multicolumn{2}{l|}{ Interest in Soaps and Sitcoms } \\
\hline & Low & High & Low Interest & High Interest \\
\hline $\mathbf{N}=$ & 951 & 2443 & 761 & 2607 \\
\hline Mean Family Importance & 2.60 & 2.72 & 2.67 & 2.77 \\
\hline & $\mathrm{t}=-6.487, \mathrm{p}=<001$ & $\mathrm{t}=-4.828, \mathrm{p}=<001$ \\
\hline
\end{tabular}

Table 3: T-test and mean difference for Family Importance a) Family Value T b) Interest in Soaps and Sitcoms ( Scale of Family Importance Variable: from 1-Low Importance to 3 High Importance)

\section{d. Regression Analysis}

As per the results, both variables are significant, so we can use them for regression analysis. The regression analysis for family importance and variables that influence it, family value and interest in soaps and sitcoms - explained 3.0\% of the variance $\left(\mathrm{R}^{2}=.023\right)$ with high significance for both. The tolerance value is 0.99 for both, which depicts that no multicollinearity issue. As it shows in Table 4, family value have stronger impact on family importance for happy life (Beta value 0.11 as compared to 0.09), both have positive correlation and that means the more you spend your leisure time with family the higher the interest in soaps and sitcoms and more interested to constitute a family for happy life.

\begin{tabular}{|l|c|c|}
\hline & Family Value & Interest in Soaps and Sitcoms \\
\hline $\mathbf{R}^{2}$ & \multicolumn{2}{|c|}{.023} \\
\hline Constant & \multicolumn{2}{|c|}{2.39} \\
\hline Slope & .070 & .041 \\
\hline Beta & 0.11 & 0.09 \\
\hline Significance & $\mathrm{p}<.001$ & $\mathrm{p}<.001$ \\
\hline Tolerance & 0.99 & 0.99 \\
\hline
\end{tabular}

Table 4: Regression analysis for Family Importance Family Value/Interest in Soaps and Sitcoms In order to draw the regression lines and to visualize the results, the formula is: $Y=b_{0}+b_{1} X_{1}+b_{2} X_{2}$ is applied, using the data from Table 4.Three regression lines represent the correlation between Family Importance and Interest in Soaps and Sitcoms related to Family Value. 


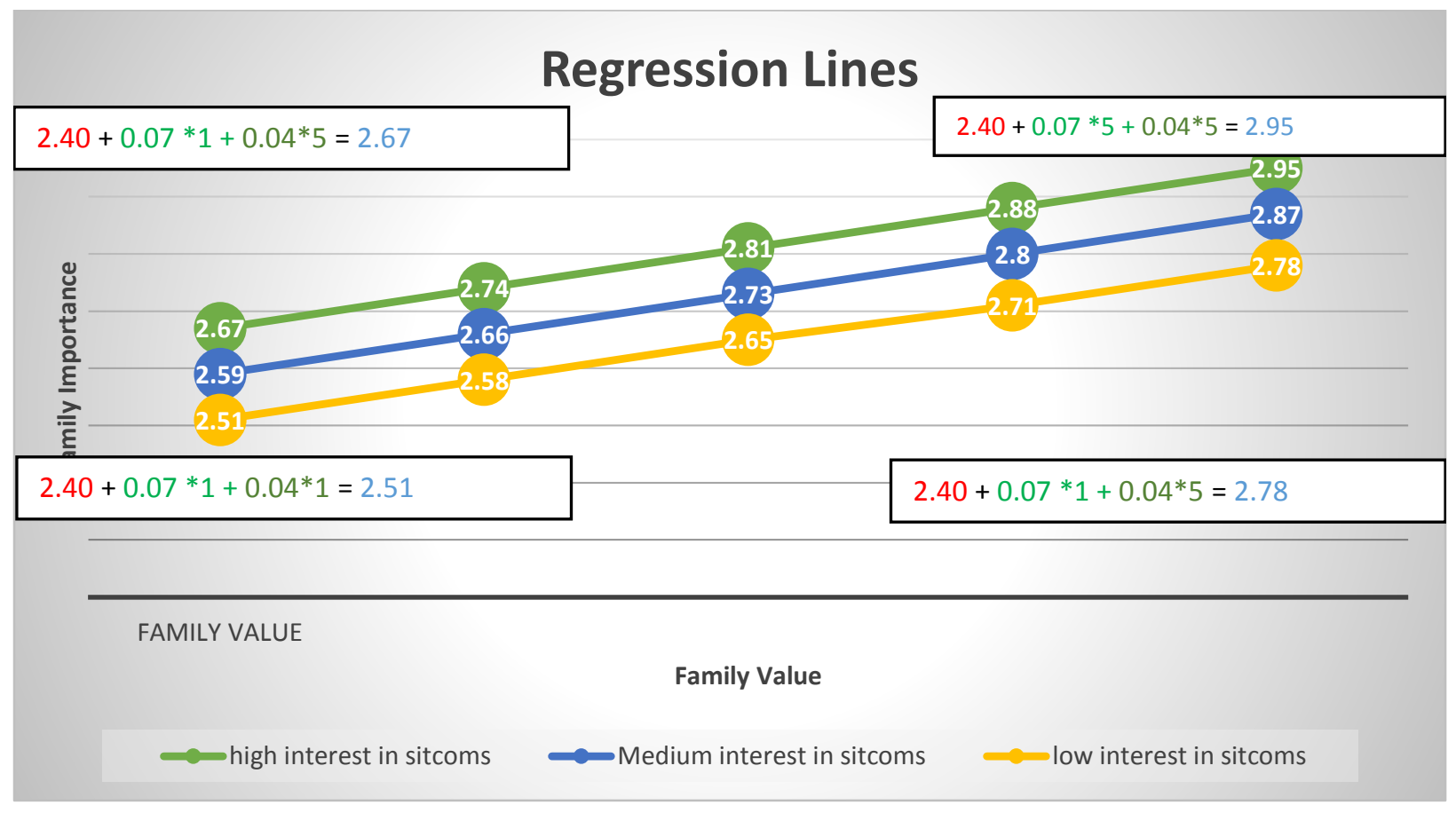

Figure 1: Regression lines for family Importance with respect to interest in soaps and sitcoms, and family value.

\section{Court Entertainment}

Imperial and royal courts have provided training grounds and support for professional entertainers, with different cultures using palaces, castles and forts in different ways. In the Maya city states, for example, "spectacles often took place in large plazas in front of palaces; the crowds gathered either there or in designated places from which they could watch at a distance."[27] Court entertainments also crossed cultures. For example, the durbar was introduced to India by the Mughals, and passed onto the British Empire, which then followed Indian tradition: "institutions, titles, customs, ceremonies by which a Maharaja or Nawab were installed ... the exchange of official presents ... the order of precedence", for example, were "all inherited from ... the Emperors of Delhi".In Korea, the "court entertainment dance" was "originally performed in the palace for entertainment at court banquets."

Court entertainment often moved from being associated with the court to more general use among commoners. This was the case with "masked dance-dramas" in Korea, which "originated in conjunction with village shaman rituals and eventually became largely an entertainment form for commoners". Nautch dancers in the Mughal Empire performed in Indian courts and palaces. Another evolution, similar to that from courtly entertainment to common practice, was the transition from religious ritual to secular entertainment, such as happened during the Goryeo dynasty with the Narye festival. Originally "solely religious or ritualistic, a secular component was added at the conclusion". Former courtly entertainments, such as jousting, often also survived in children's games.

Reading has been a source of entertainment for a very long time, especially when other forms, such as performance entertainments, were (or are) either unavailable or too costly. Even when the primary purpose of the writing is to inform or instruct, reading is well known for its capacity to distract from everyday worries. Both stories and information have been passed on through the tradition of orality and oral traditions 
survive in the form of performance poetry for example. However, they have drastically declined. "Once literacy had arrived in strength, there was no return to the oral prerogative." The advent of printing, the reduction in costs of books and an increasing literacy all served to enhance the mass appeal of reading. Furthermore, as fonts were standardised and texts became clearer, "reading ceased being a painful process of decipherment and became an act of pure pleasure". By the 16th century in Europe, the appeal of reading for entertainment was well established.

Among literature's many genres are some designed, in whole or in part, purely for entertainment. Limericks, for example, use verse in a strict, predictable rhyme and rhythm to create humour and to amuse an audience of listeners or readers. Interactive books such as "choose your own adventure" can make literary entertainment more participatory.

Comics and cartoons are literary genres that use drawings or graphics, usually in combination with text, to convey an entertaining narrative. Many contemporary comics have elements of fantasy and are produced by companies that are part of the entertainment industry. Others have unique authors who offer a more personal, philosophical view of the world and the problems people face. Comics about superheroes such as Superman are of the first type. Examples of the second sort include the individual work over 50 years of Charles M. Schulz who produced a popular comic called Peanuts about the relationships among a cast of child characters;and Michael Leunig who entertains by producing whimsical cartoons that also incorporate social criticism. The Japanese Manga style differs from the western approach in that it encompasses a wide range of genres and themes for a readership of all ages. Caricature uses a kind of graphic entertainment for purposes ranging from merely putting a smile on the viewer's face, to raising social awareness, to highlighting the moral characteristics of a person being caricatured.

In some courts, such as those during the Byzantine Empire, the genders were segregated among the upper classes, so that "at least before the period of the Komnenoi" (1081-1185) men were separated from women at ceremonies where there was entertainment such as receptions and banquets.

Court ceremonies, palace banquets and the spectacles associated with them, have been used not only to entertain but also to demonstrate wealth and power. Such events reinforce the relationship between ruler and ruled; between those with power and those without, serving to "dramatise the differences between ordinary families and that of the ruler". This is the case as much as for traditional courts as it is for contemporary ceremonials, such as the Hong Kong handover ceremony in 1997, at which an array of entertainments (including a banquet, a parade, fireworks, a festival performance and an art spectacle) were put to the service of highlighting a change in political power. Court entertainments were typically performed for royalty and courtiers as well as "for the pleasure of local and visiting dignitaries". Royal courts, such as the Korean one, also supported traditional dances. In Sudan, musical instruments such as the so-called "slit" or "talking" drums, once "part of the court orchestra of a powerful chief", had multiple purposes: they were used to make music; "speak" at ceremonies; mark community events; send long-distance messages; and call men to hunt or war.

Courtly entertainments also demonstrate the complex relationship between entertainer and spectator: individuals may be either an entertainer or part of the audience, or they may swap roles even during the course of one entertainment. In the court at the Palace of Versailles, "thousands of courtiers, including men and women who inhabited its apartments, acted as both performers and spectators in daily rituals that reinforced the status hierarchy". Like court entertainment, royal occasions such as coronations and weddings provided opportunities to entertain both the aristocracy and the people. For example, the splendid 1595 Accession Day celebrations of Queen Elizabeth I offered tournaments and jousting and other events performed "not only before the assembled court, in all their finery, but also before thousands of Londoners eager for a good day's entertainment. Entry for the day's events at the Tiltyard in Whitehall was set at $12 \mathrm{~d} "$. 


\section{Public Punishment}

Although most forms of entertainment have evolved and continued over time, some once-popular forms are no longer as acceptable. For example, during earlier centuries in Europe, watching or participating in the punishment of criminals or social outcasts was an accepted and popular form of entertainment. Many forms of public humiliation also offered local entertainment in the past. Even capital punishment such as hanging and beheading, offered to the public as a warning, were also regarded partly as entertainment. Capital punishments that lasted longer, such as stoning and drawing and quartering, afforded a greater public spectacle. "A hanging was a carnival that diverted not merely the unemployed but the unemployable. Good bourgeois or curious aristocrats who could afford it watched it from a carriage or rented a room."[39] Public punishment as entertainment lasted until the 19th century by which time "the awesome event of a public hanging aroused the[ir] loathing of writers and philosophers". Both Dickens and Thackeray wrote about a hanging in Newgate Prison in 1840, and "taught an even wider public that executions are obscene entertainments".

\section{Interpretation}

Based on statistical analysis and their results, both hypothesis are supported.

These hypotheses and their results indicates that the people who spend their leisure time with family, they consider and think that family is important. On the other hand, people who are more interested in soaps and sitcoms, they may think that, all problems and issues are part of life but family is still important for them.

The result of the regression analysis shows, both variables explain only $3.0 \%$ of the variance. It depicts that other factors have influence the importance of family for happy life. As per this paper only one variable use as dependent variable to check the influence of leisure time and watch soaps and sitcoms tested.

Further research is good to check the relationship between these concepts and can test that either a constituting a family is important for happy life depend in interest of watching cultural programs or on financial situation. Regression analysis variance is not much higher between both variables and that mean may be other factors have impact on constituting a family for life.

\section{References}

Ackroyd, Peter (2000). London: The Biography. New York: Anchor Books. ISBN 978-0-385-49771-8. p. 620.

Bailey, Peter (1998). Popular Culture and Performance in the Victorian City. Cambridge University Press. ISBN 978-0-521-57417-4.

Brett, A., Smith, M., Price, E., \& Huitt, W. (2003). Overview of the affective domain. Educational Psychology Interactive. Valdosta, GA: Valdosta State University. Retrieved November 2007, from http://www.edpsycinteractive.org/brilstar/chapters/affectdev.pdf.

Dwyer, Tim (2010). Media Convergence. Maidenhead, Berkshire, England and New York: Open University Press McGraw-Hill Education. ISBN 978-0-335-22873-7. 
Ellis, David (2007). Shakespeare's practical jokes: an introduction to the comic in his work. Lewisburg, PA: Bucknell University Press. ISBN 978-0-8387-5680-5.

Evans, R. (2004). Family matters: How schools can cope with the crisis in childrearing. San Francisco: Jossey-Bass.

Frame, Murray (2000). The St. Petersburg Imperial Theaters: Stage and State in Revolutionary Russia, 1900-1920. McFarland \& Co, Inc. Publishers. ISBN 978-0-7864-4330-7. pp. 65-66. Frame (2000).

Gay, Penny (2008). The Cambridge introduction to Shakespeare's comedies. Cambridge; New York: Cambridge University Press. ISBN 978-0-521-85668-3.

Hornback, Robert (2009). The English clown tradition from the middle ages to Shakespeare. Woodbridge Suffolk, Rochester, New York: D.S. Brewer. ISBN 978-1-84384-200-2.

Mordden, Ethan (2007). All that glittered: the golden age of drama on Broadway. New York: St. Martin's Press. ISBN 978-0-312-33898-5.

Power, Julie (3 August 2013). "Laughter and music better than drugs for dementia patients". The Sydney Morning Herald. Retrieved 3 August 2013.

Stempel, Larry (2010). Showtime: a history of the Broadway musical theater. New York: W.W. Norton \& Co. ISBN 978-0-393-06715-6.

Thorpe, Ashley (2007). The role of the chou ("clown") in traditional Chinese drama: comedy, criticism, and cosmology on the Chinese stage. Lewiston, NY: Edwin Mellen Press. ISBN 978-0-7734-5303-6.

\section{Copyrights}

Copyright for this article is retained by the author(s), with first publication rights granted to the journal.

This is an open-access article distributed under the terms and conditions of the Creative Commons Attribution license (http://creativecommons.org/licenses/by/4.0/). 